NBER WORKING PAPER SERIES

\title{
CURRENT ACCOUNT DEFICITS IN RICH COUNTRIES
}

\author{
Olivier Blanchard \\ Working Paper 12925 \\ http://www.nber.org/papers/w12925
NATIONAL BUREAU OF ECONOMIC RESEARCH
1050 Massachusetts Avenue
Cambridge, MA 02138
February 2007

MIT and NBER. Mundell-Fleming lecture given, at the IMF in November 2006. I thank Ricardo Caballero, Francesco Giavazzi, Guido Lorenzoni, Andrei Shleifer, Roberto Rigobon, and Jose Tessada for comments and discussions. I thank Tatiana Didier for excellent research assistance. The views expressed herein are those of the author(s) and do not necessarily reflect the views of the National Bureau of Economic Research.

(C) 2007 by Olivier Blanchard. All rights reserved. Short sections of text, not to exceed two paragraphs, may be quoted without explicit permission provided that full credit, including () notice, is given to the source. 
Current Account Deficits in Rich Countries

Olivier Blanchard

NBER Working Paper No. 12925

February 2007

JEL No. E62,F41

\begin{abstract}
$\underline{\text { ABSTRACT }}$
Current account imbalances have steadily increased in rich countries over the last 20 years. While the U.S. current account deficit dominates the numbers and the news, other countries, especially within the Euro area, are also running large deficits. These deficits are different from the Latin American deficits of the early 1980s, or the Mexican deficit of the early 1990s. They involve rich countries; they reflect mostly private saving and investment decisions, and fiscal deficits often play a marginal role; and the deficits are financed mostly through equity, FDI, and own-currency bonds rather than through bank lending. Yet, there appears a widely shared worry that these deficits are too large, and government intervention is required. My purpose, in this lecture, is to examine the logic of this argument. I ask the following question: Assume that deficits reflect private saving and investment decisions. Assume also that people and firms have rational expectations. Should the government intervene, and, if so, how? To answer the question, I construct a simple benchmark. In the benchmark, the outcome is first best and there is no need nor justification for government intervention. I then introduce simple distortions in either goods, labor, or financial markets, and characterize the equilibrium in each case. I derive optimal policy and the implications for the current account. I show that optimal policy may or may not lead to smaller current account deficits. I see the model and the extensions very much as a first pass. Sharper conclusions require a better understanding of the exact nature and the extent of distortions, and we do not have it. Such understanding is needed however to improve the quality of the current debate.
\end{abstract}

Olivier Blanchard

Department of Economics

E52-357

MIT

Cambridge, MA 02142

and NBER

blanchar@mit.edu 


\section{Introduction}

The last twenty years have been characterized by steadily larger current account imbalances in rich countries. This is shown in Figure 1, which shows the evolution of the cross-country standard deviation of ratios of current account balances to GDP, since 1988, for three sets of countries. The first line gives the evolution of the standard deviation for the countries which are members of the OECD today; this however is an unbalanced panel, and new members such as Mexico or Central European countries are quite different from earlier members. For this reason, the second line gives the evolution of the standard deviation for the countries that were already members of the OECD in 1988. The line is very similar to the first: The increase is not driven by the addition of the new members. The third line gives the evolution of the standard deviation for the set of countries which are today in the Euro area. The evolution is again quite similar.

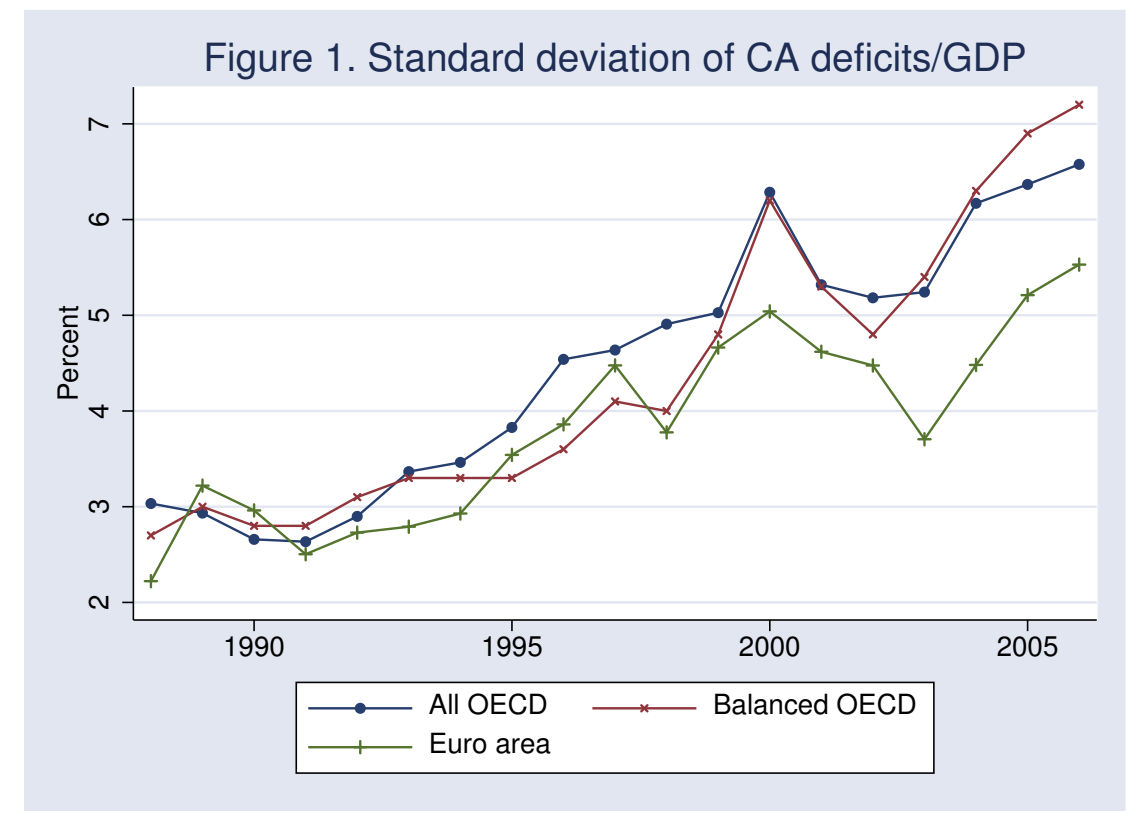

Source: OECD database.

Behind these trends are two major stories. The first is an increase in deficits within the Euro area. Countries such as Portugal and Spain are running deficits close to $10 \%$ of their GDP. The other is the increase in U.S. deficits, which now stand at around $7 \%$ of GDP. 
From the Latin American deficits of the early 1980s to the Mexican deficit of the mid 1990s, current account deficits have regularly made the news. ${ }^{1}$ Today's current account deficits are however quite different from their predecessors. The countries in deficit are rich countries. The deficits are not primarily driven by fiscal deficits, but rather by private saving and investment decisions. The deficits are typically financed through equity flows, FDI flows, and own-currency government bonds, rather than through bank lending.

Thus, many of the concerns associated with, say, the Latin American deficits of the 1980s, seem much less relevant here. Yet, policy makers and many economists worry that the deficits are too large. To caricature, there are roughly two views:

The first is known as the "Lawson doctrine", named after Nigel Lawson, the Chancellor of the Exchequer who articulated it in the 1980s. This "doctrine" is basically a restatement of the first welfare theorem: To the extent that current account deficits reflect private saving and investment decisions, that there are no distortions, and that expectations are rational, then there are no reasons for the government to intervene.

The second - and more prevalent view - could be called the "prudential" or the "IMF" view. It is that, even if deficits reflected private saving and investment decisions, distortions are present and lead to deficits that are too large. Government intervention to reduce these deficits is desirable. This view is reflected in the frequent use of such terms as "global imbalances" and "fragility" to characterize current evolutions. What exact distortions, and whether these indeed justify policies aimed at reducing deficits, has not however been worked out.

The purpose of my lecture is to explore this issue. Moving away from particulars, I take up a narrow question, namely: Assume that a current account deficit reflects private saving and investment decisions. Assume rational expectations. Is there any reason for the government to intervene, and what is the optimal form of that intervention?

It is clear that the answer depends on the existence and the specific form of distortions present in the economy. Thus, I start from a benchmark in which such distortions are absent, the equilibrium is the first-best outcome, and there is no role for government intervention. I then introduce various distortions, which

1. For a review of both facts and discussions, see Edwards (2002). 
are often thought to be important in this context. In each case, I characterize the effect of the distortion on the equilibrium, and discuss the role of policy. Clearly the role of policy is to increase welfare, not reduce the deficit per se. As we shall see, optimal policy may or may not imply a reduction in the deficit.

I see the model and its extensions very much as a first pass. Sharper conclusions require a better understanding of the exact nature and the extent of distortions, and we do not have it. Such understanding is needed however to improve the quality of the current debate.

The lecture is organized as follows.

Section 1 looks at current account deficits within the Euro area, with a particular focus on Portugal, which is, in many ways, a poster child for the issues raised in this lecture. Section 2 briefly reviews the evidence on the U.S. current account deficit, and on "global imbalances".

Section 3 develops the benchmark. My focus being on distortions, I develop the simplest benchmark needed for the purposes, namely a two-period economy, with tradables, non-tradables and leisure, log-log preferences and Cobb-Douglas production. I focus on the effects of a shift in preferences, namely a decrease in the discount factor. As is well understood, two mechanisms are at work: intertemporal reallocation of consumption (and leisure) across periods, and intratemporal reallocation of production between tradables and non-tradables. Distortions may affect either or both mechanisms, and by implication, affect current account deficits. Sections 4 to 6 look at the implications of different distortions.

The first-best equilibrium is associated with increases in the relative price of non-tradables and in the wage in the first period, and corresponding decreases in the second period. Section 4 looks at the implications of price or wage rigidities, and characterizes optimal policy. The optimal policy is to eliminate the boom/slump in non-tradables generated by price or wage rigidities; this may or may not imply a decrease in the current account deficit.

The first-best equilibrium is also associated with a decrease in the production of tradables in the first period, and an increase in the production of tradables in the second period. One may think of distortions which may make it difficult to recover and expand production in the second period. Financial constraints may make it difficult for firms to survive in the first period, or to accumulate 
the funds needed for production in the second period. Section 5 looks at the implications of such a distortion, and characterizes optimal policy. The purpose of optimal policy in this case is clearly to limit the decrease in tradables production in the first period. This may or may not imply a decrease the current account deficit.

One of the current worries of policy makers, even in the United States, is the possibility of a "sudden stop", a sharp increase in the rate of return required by foreign investors. By itself and absent domestic distortions, the possibility of a sudden stop does not change the first-best nature of the equilibrium: Private agents will take this possibility into account when making plans. The question is whether sudden stops can interact with distortions in a way that justifies government intervention. Many potential mechanisms have been identified, but most seem largely irrelevant in rich countries. Section 6 discusses these issues by extending the benchmark to a three-period model. This allows us to look at the effects of a positive probability of a sudden stop in the second period on the equilibrium, and the potential role of policy in that context.

There is a long leap from these simple exercises to actual deficits. Section 7 nevertheless takes the leap, and draws tentative policy implications, both for countries within the Euro, and for "global imbalances".

\section{Current account deficits within the Euro area}

Today, two member countries of the Euro area, Spain and Portugal, have current account deficits close to $10 \%$ of GDP. In the context of this paper, the experience of Portugal is particularly interesting, so let me start there. ${ }^{2}$

The basic macroeconomic evolutions are shown in Figure 2, which gives the evolution of the unemployment rate, and of the ratio of the current account deficit to GDP in Portugal, since 1995. The figure points to two very different periods:

The first is an economic boom, from 1995 to 2000. There is general agreement that the sources of the boom were twofold, both associated with the prospect of joining the Euro. The first was a steady decrease in real interest rates, due in large part to the disappearance of the currency premium. The second was

2. I have looked at it in more detail in Blanchard (2006a). 
the expectation that joining the Euro would accelerate convergence, and lead to higher productivity growth. Both had the effect of increasing private spending, leading both to higher output growth and to a steady increase in the current account deficit. By 2000, the unemployment rate was below $4 \%$, and the current account deficit slightly above $10 \%$ of GDP.

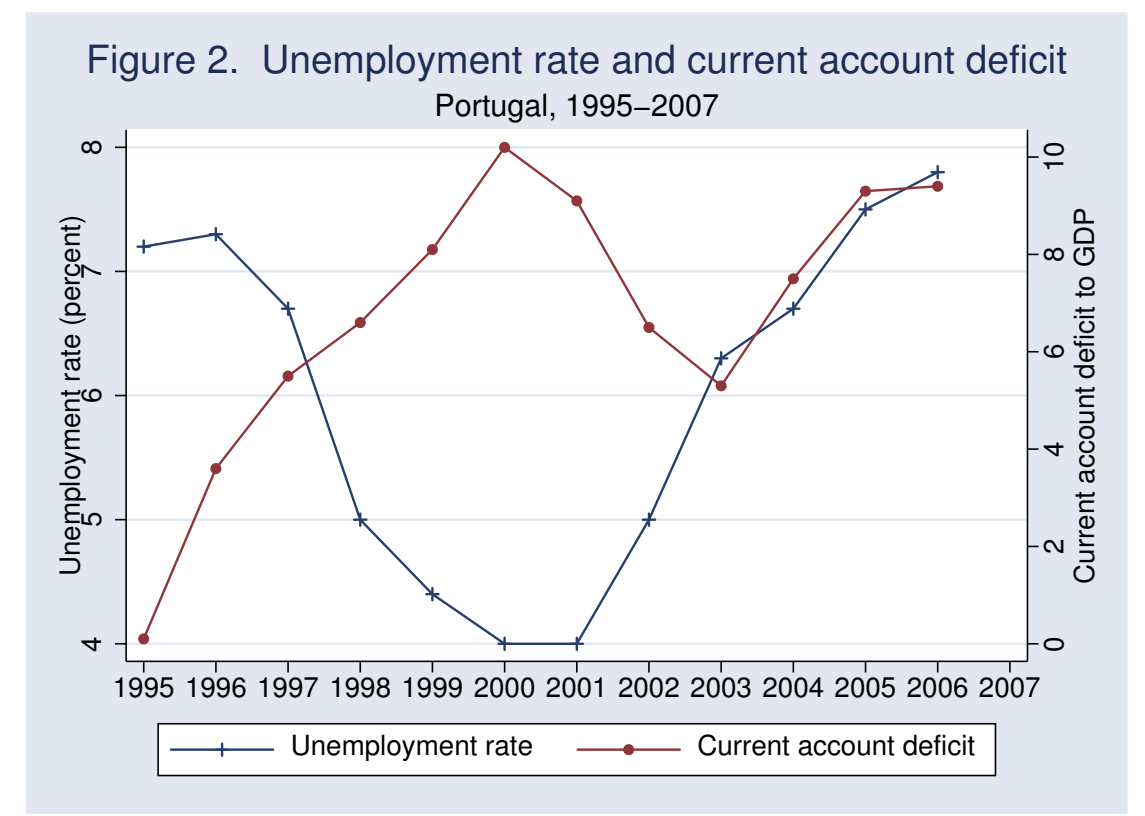

Note, as this goes to the theme of the lecture, that expectations may not have been rational, but were surely not crazy. Note also that the boom was driven by private spending, not public spending. From 1995 to 2000 , the ratio of the budget deficit to GDP decreased from 5\% to 3\%; the OECD measure of the cyclically-adjusted deficit remained roughly constant. Note finally that the boom was associated with steady real appreciation: From 1995 to 2000, unit labor costs increased by $12 \%$ relative to the Euro area average.

Expectations of faster convergence may have been reasonable. But they turned out not to be borne out by the facts: Productivity growth has remained very low, indeed lower than it was in the 1990s. Starting in 2001, private spending growth sharply decreased, leading to low growth and a steady increase in unemployment. Attempts by the government to sustain growth have led to an increase in fiscal deficits, which are now around 5\% of GDP. The unemployment rate is back around $8 \%$.

Despite the decrease in spending and the domestic slump, the current account 
deficit remains close to $10 \%$. The main reason is the continuing appreciation of Portuguese goods. Looking forward, return to higher growth and lower deficits requires a real depreciation. Given that Portugal is a member of the Euro, any such real depreciation must be achieved through lower nominal wage growth relative to productivity growth - at least vis-à-vis its Euro partners. The problem Portugal faces here is shown in Figure 3, which gives the rate of growth of wages (more precisely, compensation per employee in the business sector, in euros) and the rate of growth of labor productivity (more precisely, labor productivity per employee in the business sector) since 1996. Figure 3a gives the absolute numbers for Portugal; Figure 3b gives the numbers for Portugal as deviations from the corresponding numbers for the Euro area. Figure 3a shows that, as one might expect, high unemployment has led to a decrease in nominal wage growth; but this has come with a parallel decrease in labor productivity, so the difference between the two has remained roughly constant. Figure 3b shows that, indeed, Portuguese relative wage growth has continued to exceed relative productivity growth. In other words, Portugal has continued to lose competitiveness vis-à-vis its competitors in the Euro area. The relative depreciation required to achieve both higher growth and a smaller deficit has not yet materialized.

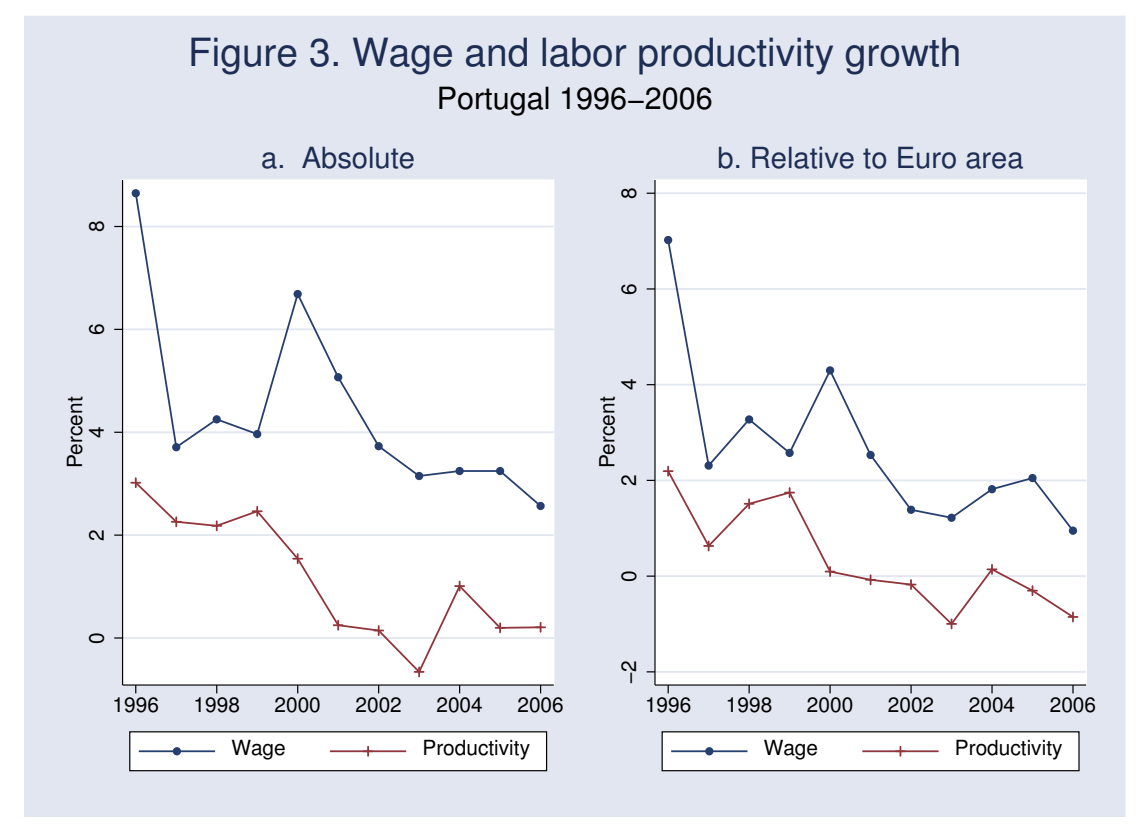

Source: OECD database. 
Should Portuguese macroeconomic policy have been different in the second half of the 1990s? Given what we now know, namely that expectations were too optimistic, the answer is obviously yes. The relevant question is however what should have been done given what was known then? Should government policies have reduced the boom, limited the appreciation, and limited the current account deficit?

The question of what should have been done during the boom in Portugal is now academic. But the question is very relevant for Spain today. Since the mid-1990s, steady growth has led to a large decrease in the unemployment rate, down from $20 \%$ to under $9 \%$ today - a decrease often referred to as the "Spanish miracle." This growth has been sustained by growth in private spending rather than public spending: The fiscal position has turned from a large deficit in the mid 1990s to a surplus of $1 \%$ of GDP today.

At the same time, growth has come with a steady real appreciation. Since 1995, unit labor costs have increased by $21 \%$ relative to the Euro area. The current account deficit has increased from rough balance in the mid 1990s to $9 \%$ of GDP today. This raises a set of obvious questions. Will Spain go through the same adjustment process as Portugal? Should government policies have been different over the last decade? Should they have limited output growth, appreciation, and the current account deficit? What should the Spanish government do today?

\section{The U.S. current account deficit}

The U.S. current account deficit has dominated both the news and much of the research in international macroeconomics in the recent past. ${ }^{3}$ My purpose here is only to point to the aspects directly relevant to the theme of the lecture, the role of private saving and investment versus fiscal policy, the way the deficit has been financed, and the rationality of expectations underlying decisions and investors's choices:

The U.S. deficit is very large, and reflected in current account surpluses visà-vis the United States in most regions of the world. The composition of the

3. A good survey of theories and facts is provided by Cline (2005). An insightful analysis of the relative roles of saving, investment, and porfolio flows, in the United States and creditor countries is given by Brender and Pisani (2007). 
corresponding current account surpluses for the third quarter of 2006 is given in Table 1. Roughly half is accounted by Asia, primarily China and Japan. Roughly one fourth is accounted for by Europe. Of the rest, an increasing but still small proportion is accounted for by the Middle East, reflecting the increase in oil prices.

Table 1. The U.S. current account deficit and its counterparts. 20063 , in billions of dollars, at annual rates.

\begin{tabular}{|c|c|c|c|c|}
\hline \multicolumn{5}{|c|}{ Total 902} \\
\hline of which & & & & \\
\hline Europe & 175 & Asia & 480 & \\
\hline Canada & 51 & China & & 288 \\
\hline Latin America & 120 & Japan & & 108 \\
\hline Middle East & 56 & & & \\
\hline
\end{tabular}

Source: BEA International Transactions. Table 11, January 2007

The U.S. deficit and the corresponding foreign surpluses have many causes. I believe that there is now a broad consensus about the following proximate causes. First, low U.S. saving, reflecting primarily low private saving, but also budget deficits. Second, high foreign saving, particularly from Asia - what Ben Bernanke (2005) has referred to as the "saving glut." Third, low foreign investment, in both Europe and Asia. Fourth, a strong preference by investors for U.S. over foreign assets. All four factors are needed to explain the combination of current account balances, the strong dollar, low world real interest rates, and apparently low expected returns on U.S. assets. ${ }^{4}$ The important point for my purposes is that fiscal policies, whether in the United States or abroad, while not irrelevant, are clearly not the main cause of the U.S. current account deficit. Private saving and investment decisions - sometimes mediated through policy, such as the combination of capital controls on capital outflows and reserve accumulation in China - around the world are.

Bank lending, which was central to the Latin American deficits, is nearly irrelevant in the case of the U.S. deficit. The composition of foreign holdings of

4. For more discussion, see in particular Bernanke (2005), Blanchard, Giavazzi, and Sa (2005), and Caballero, Farhi, and Gourinchas (2006). 
financial assets, for both stocks and flows, is given in Table 2. The composition of flows has changed over time, but the picture given by the stock numbers is very clear: In the third quarter of 2006, gross foreign holdings of U.S. assets were roughly equal to 11 trillion dollars. Of those, roughly $40 \%$ took the form of holdings of corporate equities and direct investment - a very different picture from the financing of Latin American deficits.

Table 2. Composition of foreign holdings of U.S. assets (billions of dollars). 2006

\begin{tabular}{|c|rr|}
\hline & Flows & Stocks \\
\hline Total & 1,406 & 11,946 \\
\hline T-bills & 101 & 2,069 \\
Official holdings & 111 & 1,371 \\
Private holdings & -10 & 698 \\
Corporate equities & 112 & 2,601 \\
Corporate bonds & 377 & 2,596 \\
Direct investment & 185 & 2018 \\
\hline
\end{tabular}

Source: Flow of Funds, Federal Reserve Board. Tables F.107, and L.107. Stocks: "Total U.S. financial assets held by the rest of the world", as of 2006:3. Flows: "Net acquisition of financial assets by the rest of the world", over the first three quarters of 2006.

There has been much discussion as to whether investors behind these capital flows have rational expectations. There is no question that, sooner or later, current account deficits will have to decrease, and this will most likely require a substantial real depreciation of U.S. goods. For this reason, and given the low U.S. interest rates, a number of economists have argued that foreign investors were too optimistic about expected returns on U.S. assets. If investors have a strong preference for U.S. assets however, and if they anticipate the rate of depreciation to be positive but small, then the evidence against rational expectations is much weaker. Indeed, over the past few years, financial investors rather than these economists appear to have been right about the strength of the dollar.

In short: Current "global imbalances" appear to come primarily from shifts in private saving and investment. In the absence of strong evidence to the 
contrary, the assumption that expectations are rational does not appear unreasonable. This takes us back to the question raised in this lecture. Beyond reducing the U.S. budget deficit - a reduction which indeed appears justified on its own, but, by most estimates, would only make a dent in the current account deficit - should the U.S. (and other) governments aim at reducing the remaining imbalances further? Why, and if so, how?

\section{A benchmark}

For this and the next three sections, I shall focus on the following narrow question: Assume current account deficits are the result of private saving and investment decisions. Assume expectations are rational. Should the government intervene, and if so how? To do so, I start with the following benchmark:

\section{The model}

The economy goes on - and people live for - two periods. In each period, people derive utility from the consumption of two goods, tradables and non tradables, and from leisure. ${ }^{5}$

Utility is given by:

$$
\max V \equiv U+\beta U^{\prime}
$$

where

$$
U \equiv \log (C)+\phi \log (L)
$$

and

$$
\log (C) \equiv \frac{1}{2} \log \left(C_{T}\right)+\frac{1}{2} \log \left(C_{N}\right)
$$

where primes denote second period variables, $C_{T}$ and $C_{N}$ denote the consumption of tradables and non-tradables respectively, and $L$ denotes leisure. $\beta$ is the discount factor.

As is well known, the log-log assumptions, and the implication of equal intratemporal and intertemporal elasticities of substitution eliminate a number

5. I introduce a labor-leisure choice because, when, later, I introduce distortions which imply that employment is potentially off the labor supply, I want to be able to assess the welfare cost of such a deviation and derive the optimal policy. 
of interesting issues, in particular with respect to the path of tradables consumption. ${ }^{6}$; but they are fine for the points I want to make in this lecture.

Taking tradables as the numeraire, and assuming for simplicity that the world interest rate, the interest rate in terms of tradables, is equal to zero, the budget constraint of consumer-workers is given by:

$$
q C_{N}+C_{T}+q^{\prime} C_{N}^{\prime}+C_{T}^{\prime}=A \equiv w\left(N_{T}+N_{N}\right)+w^{\prime}\left(N_{T}^{\prime}+N_{N}^{\prime}\right)+\pi+\pi^{\prime}
$$

with

$$
N_{T}+N_{N}=\bar{L}-L, \quad N_{T}^{\prime}+N_{N}^{\prime}=\bar{L}-L^{\prime}
$$

where $A$ is total wealth, $N_{T}$ and $N_{N}$ denote employment in the tradables and non-tradables sector respectively, $q$ and $w$ denote the relative price of nontradables and the wage in terms in tradables respectively. $\pi$ is profit. For the moment, there is no government; I shall introduce it later.

On the production side, competitive firms in the tradables and non-tradables sectors maximize profit subject to the following production functions:

$$
Y_{T}=N_{T}^{a}, \quad Y_{N}=N_{N}^{a}
$$

with similar equations holding for the second period. Capital is implicitly assumed to be fixed, so there is no investment decision in the model. I shall focus on current account deficits coming from variations in saving.

\section{The equilibrium}

Equilibrium requires that, in each period, the non-tradables and the labor market clear. This gives us four equations:

$$
\begin{aligned}
& C_{N}=Y_{N} \Rightarrow \frac{1}{2} \frac{1}{1+\beta} \frac{1}{q} A=\left(\frac{w}{a q}\right)^{a /(a-1)} \\
& C_{N}^{\prime}=Y_{N}^{\prime} \Rightarrow \frac{1}{2} \frac{\beta}{1+\beta} \frac{1}{q^{\prime}} A=\left(\frac{w^{\prime}}{a q^{\prime}}\right)^{a /(a-1)}
\end{aligned}
$$

and

$$
N_{T}+N_{N}=\bar{L}-L \Rightarrow\left(\frac{w}{a}\right)^{1 /(a-1)}+\left(\frac{w}{a q}\right)^{1 /(a-1)}=\bar{L}-\frac{1}{1+\beta} \frac{\phi}{w} A
$$

6. See for example Obstfeld and Rogoff (1996), 4-4, equation (34), and Dornbusch (1983). 


$$
N_{T}^{\prime}+N_{N}^{\prime}=\bar{L}-L^{\prime} \Rightarrow\left(\frac{w^{\prime}}{a}\right)^{1 /(a-1)}+\left(\frac{w^{\prime}}{a q^{\prime}}\right)^{1 /(a-1)}=\bar{L}-\frac{\beta}{1+\beta} \frac{\phi}{w^{\prime}} A
$$

where

$$
A=Y_{T}+Y_{T}^{\prime}+q Y_{N}+q^{\prime} Y_{N}^{\prime}
$$

The four equilibrium conditions are straightforward: Wealth is equal to the present discounted value of output in terms of tradables. Spending on tradables, on non-tradables, and on leisure are all proportional to wealth. The supply of non-tradables - equivalently the demand for labor from the non-tradables sector-is a decreasing function of the wage in terms of non-tradables; the demand for labor from the tradables sector is a decreasing function of the real wage in terms of tradables.

If $\beta=1$, (so the discount rate is equal to the world interest rate, namely zero), then the equilibrium is the same in both periods and the current account is balanced. It will be notationally convenient to assume that, in this equilibrium, all quantities are equal to one, i.e. that $C_{i}=Y_{i}=N_{i}=L=C_{i}^{\prime}=Y_{i}^{\prime}=$ $N_{i}^{\prime}=L^{\prime}=1$, for $i=T, N$. This in turn requires that $\bar{L}=3$ and $\phi=a / 2$. For our purposes, these restrictions are innocuous. Under this normalization also, $q=q^{\prime}=1$, and $w=w^{\prime}=a$. It is also convenient to introduce $\tilde{w} \equiv w / a$, so in the initial equilibrium $\tilde{w}=\tilde{w}^{\prime}=1$.

\section{Increased impatience and current account deficits}

I shall consider throughout the effects of an increase in impatience, $d \beta<0$, starting from $\beta=1$. Exactly the same analytical results would obtain - with a minor difference which I shall point out below - if I looked instead at a decrease in the rate of interest at which the country can borrow, $d r<0$, starting from $r=$ 0 - an experiment which would capture for example part of what happened in Portugal in the 1990s. Other shocks, for example the anticipation of increases in productivity in either the production of tradables or non-tradables next period, would lead to different analytical results, but the same general conclusions about distortions, and the role for policy.

The decrease in $\beta$ leads to two reallocations, intertemporal, and intratemporal:

- $\quad$ Being more impatient, people want to spend more and work less in the first period. 
- Consumption of non-tradables and tradables increase. The consumption of tradables increases more than the consumption of non-tradables. Taking a linear approximation and solving the equations above gives:

$$
d C_{N}=\frac{1}{2} \frac{a}{3-2 a}(-d \beta)>0 ; \quad d C_{T}=\frac{1}{2}(-d \beta)>0
$$

- $\quad$ Employment decreases (leisure increases). Employment in non-tradables increases, but employment in tradables decreases by more:

$$
\begin{gathered}
d N=-\frac{1}{2} \frac{1}{3-2 a}(-d \beta)<0 \\
d N_{N}=\frac{1}{2} \frac{1}{3-2 a}(-d \beta)>0 ; \quad d N_{T}=\frac{1}{3-2 a}(-d \beta)<0
\end{gathered}
$$

- The price of non-tradables, $q$, increases. So does the tradables product wage, $\tilde{w}$. The non-tradables product wage, $\tilde{w} / q$ decreases:

$$
d q=\frac{3}{2} \frac{1-a}{3-2 a}(-d \beta)>d \tilde{w}=\frac{1-a}{3-2 a}(-d \beta)>0
$$

The real consumption wage, $\tilde{w} / \sqrt{q}$ increases.

- Increased demand for, and decreased supply of tradables lead to a current account deficit:

$$
d(\text { current account deficit })=\frac{1}{2} \frac{3}{3-2 a}(-d \beta)>0
$$

- $\quad$ All changes hold with opposite signs in the second period.

- As $a$, the degree of returns to labor, increases, the production frontier becomes less concave, and it becomes easier to shift production between tradables and non-tradables. Thus, the price of non-tradables and the wage increase by less. The production of non-tradables increases by more, the production of tradables decreases by more, leading to a larger current account deficit.

Thus, the equilibrium response exhibits an appreciation followed by a depreciation, and, correspondingly, a decrease in the production of tradables followed by an increase later on. The current account deficit in the first period, due to both higher consumption and lower production of tradables, is offset by a current account surplus in the second period. ${ }^{7}$

7. Under the alternative assumption of a decrease in the interest rate, $d r<0$, all the equations above would hold, with $d r$ replacing $d \beta$. The only difference is that, while the decrease 
Clearly, under the assumptions made so far, the outcome is the first-best outcome, and there is no need nor justification for government intervention. The questions are then: What may be the relevant distortions in this context? How do they affect the equilibrium? And what is the optimal policy? In the next three sections, I explore three general directions: The potential role of wage or price rigidities in distorting the adjustment; the potential role of financial constraints in distorting adjustment in the tradables sector; the implications, if any, of the possibility of sudden stops, in which the country is either cut from world financial markets, or has to pay a much higher rate of return.

\section{$4 \quad$ Wage and price rigidities, and current account deficits}

During the 1990s, the increase in spending in Portugal came not only with a current account deficit, but also an output boom and a large increase in employment. This is in clear contrast to the outcome in our benchmark, where the current account deficit comes with a decrease in employment. ${ }^{8}$

The result in the benchmark is more general than it may first appear: The same would be true of an increase in expected productivity, leading to an increase in wealth, and thus to an increase in both consumption and leisure in the first period. This points to the potential role of wage and price rigidities in distorting the adjustment: The price of non-tradables and the real wage may not have increased enough to achieve the desired intratemporal reallocation between the two sectors.

The slump since 2000 points to another type of potential wage and price rigidity. In the first best, shifting from a current account deficit in the first period to a current account surplus in the second requires a decrease in the relative price of non-tradables and in the real wage. Such a real depreciation has proven difficult to achieve in Portugal. This points to something like downward wage rigidity.

There are many ways of formalizing wage and price distortions, and, in the end, the details matter. In this section, I take a first pass by simply assuming that both $q$ and $\tilde{w}$ do not adjust at all, and thus remain equal to one throughout.

in $\beta$ has no effect on wealth $A$, the decrease in $r$ increases wealth by $d A=-2 d r$.

8. One of the many problems in mapping any model to the data: The initial unemployment rate in Portugal (7\% in 1995) was probably higher than the natural rate at the time. Thus, some of the employment increase in the 1990s was probably justified. 
I assume that employment is determined by labor demand. That is, I assume that, in the tradables sector, demand is determined by profit maximization, and that, in the non-tradables sector, labor demand is determined by the demand for non-tradables. ${ }^{9}$ I leave the discussion of downward wage rigidity to later; it turns out that its effects are quite different from those in this section, and closely related to the effects of financial constraints, discussed in the next section.

\section{The equilibrium}

In addition to the assumptions that $q=q^{\prime}=1$ and $\tilde{w}=\tilde{w}^{\prime}=1$, the equilibrium is given by the condition that the non-tradables market clears each period:

$$
\begin{array}{lll}
Y_{N}=C_{N} & \Rightarrow & Y_{N}=\frac{1}{2(1+\beta)} A \\
Y_{N}^{\prime}=C_{N}^{\prime} & \Rightarrow & Y_{N}^{\prime}=\frac{\beta}{2(1+\beta)} A
\end{array}
$$

where

$$
A=2+Y_{N}+Y_{N}^{\prime}
$$

Output of non-tradables is given by the demand for non-tradables, which is proportional to wealth. Wealth is in turn equal to the sum of outputs in the tradables and non-tradables sectors over the two periods. Given $\tilde{w}=\tilde{w}^{\prime}=1$, profit maximization in the tradables sector implies constant production $Y_{T}=$ $Y_{T}^{\prime}=1$.

Together, these two equations determine output of non-tradables in both periods, and thus total output, and wealth. Wealth in turn determines the consumption of tradables in both periods, and by implication the current account balance.

\section{Increased impatience}

Consider again an increase in impatience, a decrease in $\beta$. Given wage and price

9. The usual rationalization would be to assume monopolistic competitive price-setting firms in the non-tradable sector, willing to satisfy demand so long as price exceeds marginal cost. An explicit formalization would then have an additional distortion, namely the presence of the monopolistic markup. This distortion, so long as the markup is constant, is irrelevant for my purposes. 
rigidities, only one mechanism is now at work, namely intertemporal reallocation:

- $\quad$ People again want to spend more and work less in the current period.

- Consumption of non-tradables and tradables increase, and now increase by the same amount. Denote first-best changes by a star. Then:

$$
d C_{N}=\frac{1}{2}(-d \beta)>d C_{N}^{*}>0 ; \quad d C_{T}=\frac{1}{2}(-d \beta)=d C_{T}^{*}>0
$$

The increase in the consumption of tradables is the same as in the first best. But, because the price of non-tradables does not increase, the increase in the consumption on non-tradables is higher than in the first best.

- Employment in non-tradables increases. Employment in tradables remains unchanged. So, in contrast to the first best, employment increases:

$$
\begin{gathered}
d N_{N}=\frac{1}{2 a}(-d \beta)>d N_{N}^{*}>0 ; \quad d N_{T}=0>d N_{T}^{*} \\
d N=-\frac{1}{2 a}(-d \beta)>0
\end{gathered}
$$

- Increased demand for tradables, together with an unchanged supply, lead to a current account deficit:

$$
d(\text { current account deficit })=\frac{1}{2}(-d \beta)>0
$$

Because the increase in demand for tradables is the same as in the first best, and supply does not decrease whereas it does in the first best, the current account deficit is actually smaller than in the first best. ${ }^{10}$

- $\quad$ All changes hold with opposite signs in the second period.

Thus, the economy goes through a boom cum current account deficit in the first period, a slump cum current account surplus in the second period. Both the boom and slump are inefficient. Workers would rather work less than they do in the first period, and more than they do in the second period.

\section{A role for policy?}

10. This result is not robust to more general preferences, and may not hold if the intertemporal and intratemporal elasticities of substitution are different. But the point that the current account deficit need not be larger under such rigidities, is general. 
Can policy improve the outcome and, if so, how? A full answer would require a full other lecture. Let me briefly talk about monetary and tax policy, and then deal more formally with the potential role of government spending.

Depending on the exact nature of rigidities, monetary policy can get the allocation close to or even back to first best. Take for example the case where wages are flexible and only nominal non-tradable prices are rigid ( $\tilde{w}$ is flexible and $q$ is fixed in terms of domestic currency). Then, the appropriate nominal depreciation can achieve the first-best $q$, and by implication, replicate the benchmark allocation - eliminating both the boom and the slump, while allowing for a current account deficit and intertemporal reallocation. In the presence of both wage and price rigidities, monetary policy cannot in general simultaneously replicate the first-best values of $q$ and $\tilde{w}$. But it can still improve the outcome. ${ }^{11}$

For the countries within the Euro such as Portugal, monetary policy is not available however - at least with respect to country-specific shocks. This shifts the focus towards fiscal policy. Here again, given the nature of the distortions, a sufficient rich set of taxes, say taxes on non-tradables and on labor, can achieve first best. Let me however focus on the potential role of government spending.

Let's extend the benchmark to allow utility to depend on government spending, according to:

$$
U \equiv \log (C)+\phi \log (L)+\alpha \log (G)
$$

where

$$
\log G \equiv \frac{1}{2} \log \left(G_{T}\right)+\frac{1}{2} \log \left(G_{N}\right)
$$

Assume also that all government spending is financed through lump sum taxation. To maintain the simple property that, if $\beta=1$, all steady state productions are equal to one, $\phi$ must now satisfy $\phi=(1+\alpha) a / 2$; I make this assumption in what follows.

Given the symmetry in treatment between private consumption and government spending, it is clear that, in the absence of distortions, optimal fiscal policy would simply be given by:

$$
G_{i}=\alpha C_{i}, i=T, N ; \quad G_{i}^{\prime}=\alpha C_{i}^{\prime}, i=T, N
$$

11. This is well traveled ground in the research on optimal monetary policy in an open economy. See for example Devereux and Engel (2006). 
so, that for $\beta=1$,

$$
C=\frac{1}{1+\alpha}, \quad G=\frac{\alpha}{1+\alpha}
$$

I shall call this the "neutral" component of fiscal policy, and focus on deviations from this neutral component, denoted $d g_{i}, i=T, N$ and $d g_{i}^{\prime}, i=T, N$ for the first and second period respectively.

Now turn to the role of government spending in the case of price and wage rigidities. Given the symmetry of first-period and second-period effects of the decrease in $\beta$, it follows that the optimal policy satisfies $d g_{N}^{\prime}=-d g_{N}$ and $d g_{T}^{\prime}=-d g_{T}$. Thus, we can focus on the determination of just $d g_{N}$ and $d g_{T}$.

Going through the characterization of the equilibrium, now in the presence of the government, gives:

$$
d Y_{N}=\frac{1}{2}(-d \beta)+d g_{N}, \quad d C_{N}=\frac{1}{2} \frac{1}{1+\alpha}(-d \beta), \quad d G_{N}=\frac{1}{2} \frac{\alpha}{1+\alpha}(-d \beta)+d g_{N}
$$

An increase in government spending on non-tradables increases output of nontradables one-for-one. It has no effect on the consumption of non-tradables. The reason why consumption is unaffected is the absence of a wealth effect: Any increase in $d g_{N}$ is expected to be offset by an equal decrease in $d g_{N}^{\prime}$; any increase in $d Y_{N}$ induced by higher $d g_{N}$ is also expected to be offset by an equal decrease in $d Y_{N}^{\prime}$ :

$$
d Y_{T}=0, \quad d C_{T}=\frac{1}{2} \frac{1}{1+\alpha}(-d \beta), \quad d G_{T}=\frac{1}{2} \frac{\alpha}{1+\alpha}(-d \beta)+d g_{T}
$$

An increase in government spending on tradables has an effect neither on production nor on consumption of tradables. Thus, it affects the current account deficit one-for-one. The reason why consumption is unaffected is again the absence of a wealth effect. Any increase in $d g_{T}$ is expected to be offset by an equal decrease in $d g_{T}^{\prime} \cdot{ }^{12}$

Thus, the right tool to reduce the inefficiency is clearly $d g_{N}$. A negative $d g_{N}$ in the first period, associated with a positive $d g_{N}^{\prime}$ in the second period allows the government to eliminate the boom and the slump. A negative $d g_{T}$, followed by a positive $d g_{T}^{\prime}$ would reduce the current account, but have no effect on the inefficiency. This suggests that the optimal policy is to use only $d g_{N}$ and $d g_{N}^{\prime}$.

12. The extreme form of some of these results depends again on the log-log restrictions. But the message about the relative effects of $d g_{N}$ and $d g_{T}$ is general. 
Indeed, under a quadratic approximation to the utility function and a linear approximation to the equilibrium conditions, the optimal policy is given by:

$$
d g_{N}=-\frac{\alpha(1+a)}{2(\alpha+a+a \alpha)}(-d \beta)<0
$$

This policy leaves the current account deficit unaffected, but reduces the boom and the slump.

The message from this first extension is that price and wage rigidities may well distort the allocation. The optimal policy may not however be to reduce the current account deficit. Indeed, in the simple case worked out here, the current account deficit is unaffected. One question is whether more asymmetric forms of rigidity, such as downward wage rigidity, would lead to different conclusions. The answer is yes, and I shall return to this below.

\section{$5 \quad$ Financial constraints, and current account deficits}

Adjustment in the first best implies first a decrease, then an increase (equal to twice the initial decrease) in tradables output. One worry is that it may indeed be difficult for the tradables sector to expand after a long period of appreciation and low production.

One may think of a number of reasons why this might be. Internal costs of adjustment are not the issue: These will indeed affect the adjustment, and thus affect in turn first-period decisions and the current account deficit; but, absent other considerations, the outcome will still be the first-best outcome, and there is no role for government policy. Other distortions may however be relevant. Krugman (1987) emphasized for example external learning by doing, and the fact that a long period of low production may lead to permanently lower productivity. Others have emphasized financial constraints, the fact that the tradables sector may not, after a long period of low profits, have the funds needed to invest and increase production later on.

I explore this idea by making a simple, if highly reduced form, assumption. I assume that production of tradables in the second period is given by:

$$
Y_{T}^{\prime}=\min \left(Y_{T},\left(\frac{\tilde{w}^{\prime}}{a}\right)^{\frac{a}{a-1}}\right)
$$


Production of tradables is equal to the minimum of the profit maximizing level of output in the second period, and the level of production of tradables in the first period. For the shock we shall look at, namely an increase in impatience, the constraint is binding, and second-period tradables output is thus constrained to be no larger than first-period output.

Some generality would be obtained by allowing the parameter in front of first period output to be different from one; but this is inessential. A rough justification for this assumption may be the following: Tradables firms can borrow up to some multiple of first period earnings - which are proportional to output - to pay the second-period wage bill, which is itself proportional to second-period output. A more explicit and richer micro-grounding is given by Caballero and Lorenzoni (2006): During the appreciation period, firms incur losses. Because of financial constraints, these losses may force them to decrease their capital stock beyond what would be efficient, putting constraints on the recovery in the second period.

Another issue is whether firms in the tradables sector internalize this constraint when taking output decisions in the first period (and so choose a higher level of production in the first period in order to relax the constraint on production in the second period). This depends on whether the constraint holds at the level of the firm or for the tradables sector as a whole. I assume that the constraint holds for the sector as a whole (that there is, for example, a segmented financial market where only tradables firms can participate), and so firms do not internalize it in taking decisions in the first period.

\section{The equilibrium}

Equilibrium requires that the tradables market and the labor market each clear in each period, yielding four equilibrium conditions. Let me introduce the government from the start, so as to prepare for the discussion of policy later on: 


$$
\begin{aligned}
& C_{N}+G_{N}=Y_{N} \Rightarrow \frac{1}{2} \frac{1}{1+\beta} \frac{1}{q} A+d g_{N}=\left(\frac{\tilde{w}}{q}\right)^{a /(a-1)} \\
& C_{N}^{\prime}+G_{N}^{\prime}=Y_{N}^{\prime} \Rightarrow \frac{1}{2} \frac{\beta}{1+\beta} \frac{1}{q^{\prime}} A+d g_{N}^{\prime}=\left(\frac{\tilde{w}^{\prime}}{q^{\prime}}\right)^{a /(a-1)} \\
& N_{T}+N_{N}=\bar{L}-L \Rightarrow \tilde{w}^{1 /(a-1)}+\left(\frac{\tilde{w}}{q}\right)^{a /(a-1)}=\bar{L}-\frac{1}{1+\beta} \frac{1}{\tilde{w}} A \\
& N_{T}^{\prime}+N_{N}^{\prime}=\bar{L}-L^{\prime} \Rightarrow \tilde{w}^{1 /(a-1)}+\left(\frac{\tilde{w}^{\prime}}{q^{\prime}}\right)^{a /(a-1)}=\bar{L}-\frac{\beta}{1+\beta} \frac{1}{\tilde{w}^{\prime}} A
\end{aligned}
$$

where

$$
A=\left(Y_{T}+Y_{T}^{\prime}+q Y_{N}+q^{\prime} Y_{N}^{\prime}\right)-\left(q d g_{N}+q^{\prime} d g_{N}^{\prime}+d g_{T}+d g_{T}^{\prime}\right)
$$

Leaving aside the additional terms coming from the presence of fiscal policy, the only difference between these equations and those of the benchmark are in the specification of the second-period demand for labor in the tradables sector in the fourth equation: Assuming the constraint is binding, labor demand in the second period is equal to labor demand in the first period, and so depends on the first-period rather than the second-period real wage.

The way fiscal policy enters is also straightforward. $d g_{N}$ and $d g_{N}^{\prime}$ directly affect the demand for non-tradables, both directly and through their effect on wealth. $d g_{T}$ and $d g_{T}^{\prime}$ affect spending and labor supply only to the extent that they affect wealth. This is what is shown in the last equation.

\section{Increased impatience}

Consider now the effects of an increase in impatience, $d \beta<0$, assuming first that there is no fiscal policy response, so all $d g$ 's are equal to zero. Then:

- Just as in the benchmark, people want to intertemporally substitute, enjoy more consumption and more leisure in the first period. But they now also take into account that lower tradables production in the first period implies lower tradables production in the second period, and thus lower income in the second period. This leads to a decrease in their wealth, and thus lower consumption and higher labor supply in both periods.

- Thus, the demand for tradables and non-tradables increases, but, in both cases, by less than in the first best: 


$$
\begin{aligned}
& d C_{N}+d G_{N}=d Y_{N}=\frac{a}{6}(-d \beta)>0 \\
& d C_{N}^{\prime}+d G_{N}^{\prime}=d Y_{N}^{\prime}=\frac{a}{6}(-d \beta)>0 \\
& d C_{T}+d G_{T}=\frac{3-2 a}{6}(-d \beta)>0 \quad d C_{T}^{\prime}+d G_{T}^{\prime}=-\frac{3+2 a}{6}(-d \beta)<0
\end{aligned}
$$

- $\quad$ Both because the increase in non-tradables output in the first period is smaller than in the first best, and because the decrease in labor supply is smaller than in the first best, the decrease in tradables output in the first period is also smaller than in the first best. As the financial market constraint is binding, the decrease in tradables output in the second period is the same as in the first period.

$$
d Y_{T}=-\frac{a}{3}(-d \beta)<0 \quad d Y_{T}^{\prime}=-\frac{a}{3}(-d \beta)<0
$$

- Higher demand and lower supply of tradables lead to a current account deficit. The current account deficit is however smaller than in the first best:

$$
d\left(\text { current account deficit }=\frac{1}{2}(-d \beta)>0\right.
$$

- Because the increase in the demand for non-tradables is smaller than in the first best, so are the initial appreciation and wage increase:

$$
\begin{array}{rlrl}
d q & =\frac{1-a}{2}(-d \beta)>0 & d q^{\prime} & =-\frac{1+a}{2}(-d \beta)<0 \\
d \tilde{w} & =\frac{1-a}{3}(-d \beta)>0 & d \tilde{w}^{\prime}=-\frac{a+2}{3}(-d \beta)<0
\end{array}
$$

- In contrast to the first distortion, adjustments in the second period are not mirror images of those in the first period. Output of tradables goes down in both periods, output of non-tradables goes up. The current account deficit comes with a slump in the tradables sector.

The misallocation of labor between the two sectors in the second period leads to a decrease in wealth, and to a first-order loss in welfare:

$$
d A=-\frac{4}{3}(-d \beta)<0 ; \quad d V=-\frac{a(1+\alpha)}{6}(-d \beta)<0
$$




\section{Optimal fiscal policy}

Given this outcome, is there a role for fiscal policy? Intuition suggests that there is: A decrease in $G_{N}$ can decrease the demand and the production of non-tradables, and thus increase the production of tradables in the first period and, by implication, in the second period. Increases in either $G_{T}$ or $G_{T}^{\prime}$, while they have no direct effect on the production of tradables, decrease wealth and thus private spending, including spending on non-tradables. This again increases production of tradables in the first period, and by implication, in the second period. This suggests that optimal policy includes decreases in $G_{N}$, and increases in $G_{T}$ and $G_{T}^{\prime}$.

\section{Figure 4. Optimal fiscal policy}
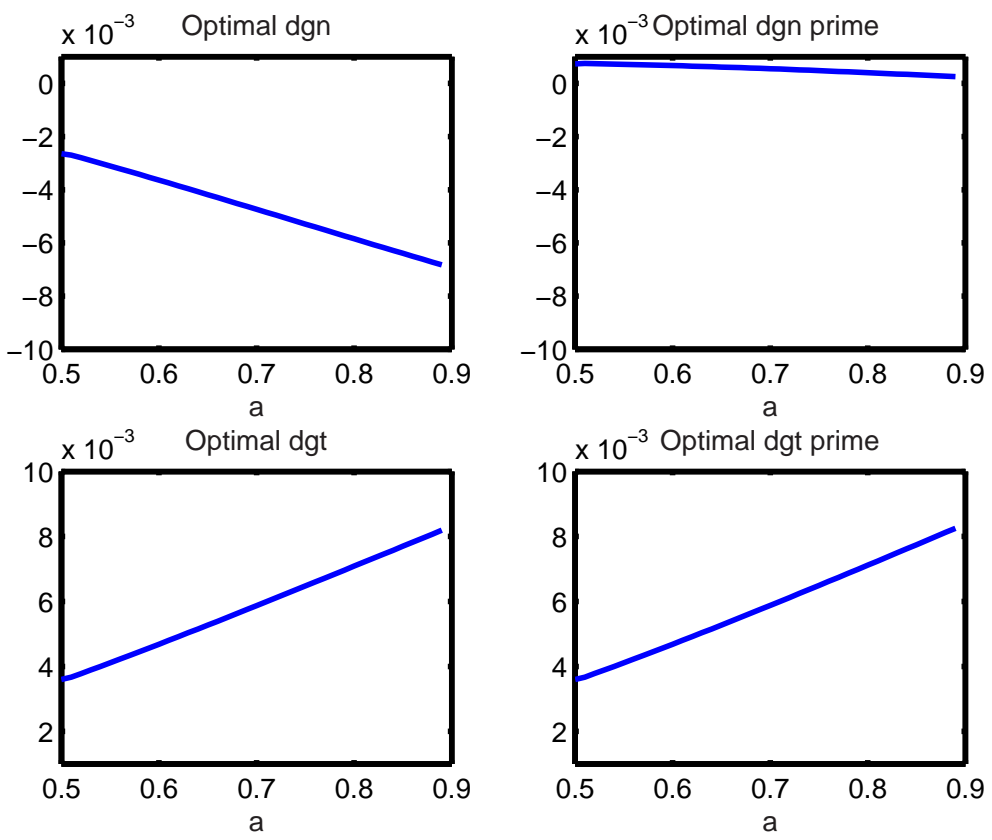

This is indeed the case. Figure 4 gives the optimal values of the $d g_{i}$ 's (the deviation from neutral fiscal policy) obtained by maximization of a secondorder approximation to the utility function subject to a linear approximation of the equilibrium conditions given above. The figure gives values for $\alpha=0.5$ and $a$ ranging from 0.5 to 0.9 . It shows that, indeed, optimal $d g_{N}$ is negative, optimal $d g_{N}^{\prime}$ is close to zero, and optimal $d g_{T}$ and $d g_{T}^{\prime}$ are equal to each other and positive. 
Figure 5 shows the deviation of the current account deficit from its value absent fiscal policy. Note that the current account deficit is actually larger under optimal fiscal policy (for example, 0.004 higher if $a=0.9$ ). The reason is that while the decrease in government spending on nontradables increases the production of tradables, the optimal policy also requires an increase in government spending on tradables, which directly increases the current account deficit. I see this result not as a major implication, but, again, as a warning that the presence of distortions does not necessarily require policies aimed at reducing the current account deficit.

\section{Figure 5. Current account deficit, with and without fiscal policy}

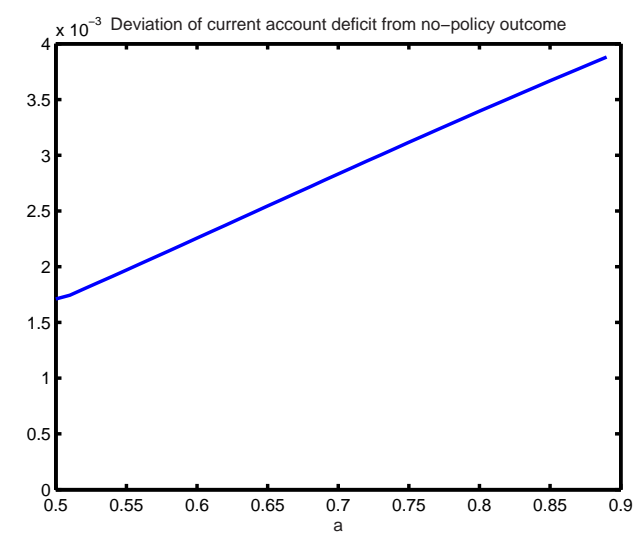

The message from this second extension is that, to the extent that financial constraints matter in the tradables sector, there is indeed a role for policy to limit reallocation in the first period. The optimal policy however may or may not decrease the current account deficit.

How important are the relevant financial market imperfections, and how much do they limit reallocation? ${ }^{13}$ One might guess that tradables firms in rich countries would be among those with the best access to financial markets, and thus would be least likely to be financially constrained. But, as far as I can tell, we do not know. Recent work by Calvo, Izquerdio, and Talvi (2006) suggests that, even in Argentina after the collapse and the disorganization of credit mar-

13. The question has been explored, in a different but related context, by Caballero and Hammour (2005), who have looked at whether recessions lead to the disappearance of low productivity versus financially constrained firms. 
kets, tradables firms have been able to increase production in response to the (admittedly very large) peso depreciation.

Let me return briefly to an issue I left aside in the previous section, namely the implications of downward wage rigidity. Under the assumption that the wage in terms of tradables can increase but cannot decrease, the equilibrium looks very much like the equilibrium I have just characterized. In response to an increase in impatience, downward rigidity prevents the first-best reallocation of production: The real wage goes up in the first period, but cannot go down in the second period, leading to lower production of both tradables and nontradables in the second period. Anticipations of lower future income, and thus lower wealth (relative to first best), lead people to want to consume less and work more in the first period (again, relative to first best). The result is a lower current account deficit and boom in the first period, and an output slump cum current account surplus in the second period.

Note that, under financial market constraints, the labor market clears in the second period, but the allocation is distorted towards non-tradables; under downward rigidity, the labor market does not clear, and both the production of tradables and non-tradables are lower. In terms of policy however, the conclusions are roughly similar. Optimal policy requires measures which limit the wage increase in the first period, either by decreasing demand for non-tradables or the supply of labor.

\section{$6 \quad$ Sudden stops, distortions, and policy}

I suspect that, up to this point, I have not dealt with the main worry in the mind of a number of economists and policy makers, namely "sudden stops." This is the worry that a country may find itself suddenly cut from world financial markets, or more realistically for a country such as the United States, that foreign investors may ask suddenly for a much higher rate of return. ${ }^{14}$

That sudden stops can happen is amply demonstrated by history, most recently by the Asian crisis. ${ }^{15}$ That they can lead to sharp depreciations, and sometimes

14. This is for example a recurring theme in Nouriel Roubini's blog commentary on the U.S. current account deficit.

15. The Asian crisis indeed shows that sudden stops can happen even in the absence of large current account deficits. 
to sharp drops in output, is also well documented. What is less clear is what role they imply for policy vis-à-vis current account deficits.

Put simply, the possibility of sudden stops, i.e. the willingness - or lack offoreign investors to lend to the country, are not a distortion per se, but just a statement about the borrowing opportunities open to the domestic economy. Under the assumption of rational expectations, borrowers will take this possibility into account, and be more careful in their borrowing. Absent other distortions, the outcome will still be the first-best outcome, implying no role for policy. Put another way, the argument for policy must rely on the interaction of sudden stops and specific distortions - and in the context of this lecture, distortions relevant for rich countries with well-developed financial markets.

Again, a treatment of the issues would require a full other paper. I shall limit myself to a simple formalization of the arguments above, using it as a basis for a more focused discussion.

It is obviously impossible to discuss sudden stops in our two-period model: Repayment takes place in the second period in any case. Thus, the first step is to extend the benchmark model to three periods, so:

$$
V \equiv U+\beta^{\prime} U^{\prime}+\beta^{\prime \prime} U^{\prime \prime}
$$

where $U$ is defined over tradables, non-tradables, and leisure in the same way as before. Assume that initially, $\beta^{\prime}=\beta^{\prime \prime}=1$ and that the world interest rate is equal to zero, so the equilibrium in each period is the same as in the benchmark.

We can now introduce the possibility of sudden stops by assuming that, in the second period, the country is cut from world markets with some probability $p$. It is clear that the possibility of sudden stops will affect borrowing decisions. Take the extreme case where $d \beta^{\prime}=0$, and $d \beta^{\prime \prime}<0$, and $p=1$. In this case, people want to shift consumption from the third to the first two periods, but the world market is closed from the second period on. In this case, people will not change their spending decisions, and the current account deficit in the first period is equal to zero.

\section{Increased impatience}

Suppose that $d \beta^{\prime}=d \beta^{\prime \prime}<0$, so people want to shift utility from the second and 
third period to the first. And suppose that, in the second period, the country is cut from world markets with probability $p$-and thus functions in autarchy in the third period, or, with probability $(1-p)$, can continue to borrow at the world interest rate, $r=0$. We can then solve for optimal consumption and labor supply, and by implication for the current account deficit:

- The current account deficit in period 1 is given by:

$$
d(\text { current account deficit })=\frac{1}{3+p} \frac{4}{2-a}\left(-d \beta^{\prime}\right)
$$

The larger the probability of the sudden stop, the lower the initial increase in consumption, the lower the initial decrease in production, and the lower the initial current account deficit.

- Denote by $q_{c}^{\prime}$ the relative price of non-tradables in period 2 if a sudden stop takes place (if the world market closes, so "c" stands for closed). Then:

$$
\begin{gathered}
d q=\frac{1}{3+p} \frac{4(1-a)}{2-a}(-d \beta)>0 \\
d q_{c}^{\prime}=-d q=-\frac{1}{3+p} \frac{4(1-a)}{2-a}(-d \beta)<0, \quad d q_{c}^{\prime \prime}=0
\end{gathered}
$$

The lower the probability of a sudden stop, the larger the initial appreciation, and so the larger the depreciation if a sudden stop actually takes place.

A positive probability of a sudden stop, and of a large associated depreciation, are clearly the reason why some economists worry about the current account deficits. Are they right?

First, it is clear that, in the case of the United States today, financial markets do not give a high probability to such an event. A positive probability of a sudden stop should be reflected in an upward sloping term structure - at least relative to the "world term structure". In the model, defining the short rate as the interest rate in terms of tradables between period 1 and period 2, and the long rate as the interest rate in terms of tradables between period 1 and period 3 , the slope of the term structure is given by:

$$
r_{L}-r_{S}=\frac{p}{3+p}(-d \beta) \geq 0
$$

It is thus increasing in $p$. In contrast, one of the characteristics of the current 
U.S. term structure is that it is surprisingly flat (the so called "Greenspan conundrum").

Second, and more generally, in the absence of other distortions, the equilibrium we have just characterized is the first-best outcome, and there is no reason for the government to intervene. It must therefore be that these economists are worried about the interaction between the sharp depreciation and distortions.

From the Latin American and Asian experiences, we have learned that such distortions may indeed be present. Financial imperfections may lead to a contraction rather than an expansion of the tradables sector in response to the depreciation. ${ }^{16}$ The relevant question for this lecture is whether the factors that played a central role in Latin America and Asia are relevant for rich countries, in particular for the United States, where the current account deficit has been financed through direct investment, equity finance, and own-currency bonds rather than bank loans. The first pass answer must be that they are much less relevant, if relevant at all.

Financial market imperfections, along the lines of those explored in the previous section, may however be relevant. In response to a sharp and partly unexpected depreciation, the tradables sector may face financial constraints and be limited in its ability to increase output. This leads to a formalization which combines sudden stops with financial market distortions. I see no reason to expect dramatically different results from those obtained in the previous section. There is now an argument for using policy, so as to limit the decline in tradables output in the first period; it is still not clear however that the optimal policy implies a reduction of current account deficits.

These are casual remarks, and it may well be that a stronger theoretical case for deficit reduction can be made. The framework above provides perhaps a useful starting point. I believe it is fair to say however that the case is less obvious, on both theoretical and empirical grounds, than its proponents have made it sound.

16. This is very well traveled ground. For a simple, but formal, discussion, see for example Caballero and Krishnamurthy (2002). 


\section{$7 \quad$ Back to the Euro area, and to global imbalances}

This lecture has taken a step back from current policy debates and looked at the case for policy intervention in the face of large current account deficits in rich countries. It has made a few simple methodological points: The case for intervention must rely on the presence of distortions. Which distortions, and thus what intervention is required, must be spelled out explicitly. For the distortions I have looked at, optimal policy typically did not involve current account deficit reduction.

It is a large leap from the examples I have worked out to an assessment of optimal policy vis-à-vis deficits within the Euro area, or vis-à-vis current "global imbalances". The main purpose of my lecture was to stimulate research so as to eventually get there. But it is too tempting not to try to jump now, and so I shall not resist. The usual caveats apply.

\section{Current account deficits in the Euro area}

In the case of Euro-countries, the main distortions would appear to be wage and price rigidities. These rigidities are clearly present, and together with the fixed exchange rate, affect the adjustment of real wages and relative prices.

These rigidities in turn imply a role for fiscal policy, and for the use of government spending. The specific form of fiscal policy depends on the specific form of rigidities, whether or not, for example, wage rigidities are symmetric. In the current low inflation environment, nominal wages may well be more downward rigid. More work clearly needs to be done here, both on the exact nature of the rigidities, and on their policy implications. But, as simple as it is, the analytical exercise I have carried out points to two important issues, which are insufficiently discussed in the current European policy debate:

The first is the potentially important role of active fiscal policy. It may well be that the priority, for the time being, is to reduce budget deficits so as to recover the margin of maneuver that fiscal policy needs to operate optimally. But we should think harder about to use this margin when it becomes available.

The second is that, while fiscal policy can help, it is a poor instrument, and the outcome may still be far away from first best. This strongly suggests that governments should not take wage and price rigidities as given. Indeed, a better 
way of thinking about country-specific macroeconomic policy in the context of countries in a common currency area is to think of the joint use of wage and fiscal policies.

This is not the usual call for lowering "labor market rigidities", or for more "wage flexibility". It is a call for a better coordination of wage and fiscal adjustments. It is based on the hindsight that it would have been better for Portugal to combine fiscal contraction and wage increases in the 1990s, in exchange for fiscal expansion and wage decreases in the 2000s.

How could this have been achieved in Portugal? Could it be achieved in Spain, or in the next country to experience a country-specific demand boom? Nobody can be sure, but governments should try. I believe that, in the European context, this requires a centralized information and bargaining structure, in which social partners regularly discuss and potentially agree on the macroeconomic situation and the measures to be taken. The presence of such a bargaining structure surely is only a necessary condition: There may not have been agreement about what needed to be done in Portugal in the 1990s, any more than there may be agreement about what needs to be done today. But it surely increases the chances of success. Such a structure is clearly more difficult, if not impossible, to put in place when the initial adjustment requires workers to accept a decrease in wages - as is the case in Portugal today. This is why it has to be put in place before the crises hit, and why I see it as a high priority in Euro area countries.

Absent such structures, the weight of the adjustment will fall on only one instrument, fiscal policy. This instrument is limited in what it can do. And it is likely to be misused. For the first half of the 2000s, Portugal tried to limit its slump through a fiscal expansion and an increase in fiscal deficits, clearly not the right instrument when the problem is with external demand. The same danger looms in Spain, where policy makers talk about using a fiscal expansion if and when internal demand decreases. What will be needed then is a depreciation and an increase in external demand. Using a fiscal expansion will only delay the required adjustment.

\section{Global imbalances}

In the case of global imbalances, the major countries involved are not constrained by exchange rate regimes (China is free to peg or not), so wage and 
price rigidities seem less relevant. It is also hard to think of financial imperfections which would prevent a large increase in US tradables output in response to a depreciation. So, unless I have left out some central imperfections, the firstpass answer must be that the case for government intervention, in the United States or elsewhere, is weak.

This is however only a first-pass answer. The reason is that the shifts in private saving and private investment which underlie current imbalances are themselves due, in part, to distortions. For example, high saving in China reflects in part the lack of retirement and health insurance, and thus precautionary saving on the part of Chinese individuals. ${ }^{17}$ Low investment in parts of Asia reflects poor financial intermediation. Low saving in the United States reflects in part public dissaving; private saving itself maybe based on incorrect expectations about retirement benefits and health care.

Reducing these distortions, or in the last case, reducing the budget deficit, is clearly desirable: China should provide better retirement and health insurance to its citizens; this would increase their welfare. The United States government should reduce its budget deficit, and so on. Such policy changes are indeed likely to reduce imbalances: To the extent that providing insurance decreases saving and increases internal demand, China may find that it has to reduce external demand through an appreciation of the RMB, which will reduce China's current account surplus. As it reduces its fiscal deficit, the United States may find that maintaining output at its natural level requires a decrease in interest rates and a depreciation of the dollar, resulting in a reduction in its current account deficit. But the purpose of these reforms should be the reduction of distortions, not the reduction of current account deficits per se.

This raises a last question, and a central question for the IMF. Is there a strong case for coordination of these changes and reforms across countries? I think the answer is no, with however a caveat to which I return below. It is basically in the interest of each country to implement such reforms, whether or not the others embark on their own reforms. It is in the interest of China to provide better insurance and health care to its citizens, whether or not the United States reduces its budget deficit. It is in the interest of the United States to reduce its budget deficit, whether or not Asia improves its financial intermediation system. These adjustments will require adjustments in exchange

17. See for example Blanchard and Giavazzi (2006). 
rates and interest rates; but these can be achieved by domestic central banks through monetary policy. The case for international coordination, at least on economic grounds, seems weak. The caveat mentioned above is a methodogical one, in line with the general argument of this lecture: The world we are looking at is very much a second-best world, in which, at least in principle, the removal of some distortions and not others could make things worse. I cannot think of any realistic example in this context, but this is hardly proof that they do not exist. Again, looking more closely at distortions, and working out their implications, is needed to improve our understanding. 


\section{References}

Bernanke, Ben, 2005, "The global saving glut and the U.S. current account deficit," Sandridge Lecture, Virginia Association of Economics, Richmond, Virginia (March)

Blanchard, Olivier, 2006a, "Adjustment within the Euro: The difficult case of Portugal," MIT Working Paper, forthcoming, Portuguese Economic Journal

Blanchard, Olivier, and Francesco Giavazzi, 2006, "Rebalancing growth in China. A three-handed approach," China and the world economy, 14(4):1-20 (JulyAugust)

Blanchard, Olivier, Francesco Giavazzi, and Filipa Sa, 2005, "International investors, the U.S. current account, and the dollar," Brookings Papers on Economic Activity (Spring)

Brender, Anton, and Florence Pisani, 2007, "Les déséquilibres financiers internationaux", La Découverte, Paris

Caballero, Ricardo, Emmanuel Farhi, and Pierre-Olivier Gourinchas, 2006, "An equilibrium model of "global imbalances" and low interest rates," MIT working paper 06-02 (January)

Caballero, Ricardo, and Mohamad Hammour, 2005, "The cost of recessions revisited: A reverse-liquidationist view," Review of Economic Studies, 72:313341 (April)

Caballero, Ricardo, and Arvind Krishnamurthy, 2002, "A dual liquidity model for emerging markets," American Economic Review, 92(2):33-37 (May)

Caballero, Ricardo, and Guido Lorenzoni, 2006, "Persistent appreciations, overshooting, and optimal exchange rate interventions," mimeo MIT (October)

Calvo, Guillermo, Alejandro Izquierdo, and Ernesto Talvi, 2006, "Phoenix miracles in emerging markets: Recovering without credit from systemic financial crises, " NBER working paper 12101 (March)

Cline, William, 2005, The United States as a Debtor Nation, Institute for International Economics, Washington DC.

Devereux, Michael, and Charles Engel, 2006, "Expenditure switching versus real exchange rate stabilization: Competing objectives for exchange rate policy," NBER working paper 12215 (May) 
Dornbusch, Rudiger, 1983, "Real interest rates, home goods, and external borrowing, " Journal of Political Economy, 91-1:141-153

Edwards, Sebastian, 2002, "Does the current account matter?" in Preventing currency crises in emerging markets Sebastian Edwards and Jeffrey Frankel eds, University of Chicago Press, 21-75

Krugman, Paul, 1987, "The narrow moving band, the Dutch disease, and the competitive consequences of Mrs Thatcher, "Journal of Development Economics, 27:41-55

Obstfeld, Maurice, and Kenneth Rogoff, 1996, Foundations of international macroeconomics, MIT Press 